\title{
Xaquín Marín: arte y compromiso en el humor gráfico gallego
}

\author{
Félix CABAllero WANGÜEMERT \\ Investigador y periodista \\ felixcaballero@hotmail.com
}

Recibido: 2 de febrero de 2016

Aceptado: 7 de julio de 2016

\begin{abstract}
Resumen
A partir de 1970 se abre un periodo de esplendor en el humor gráfico gallego que tiene como uno de sus principales protagonistas a Xaquín Marín. El dibujante ferrolano, que desde 1988 colabora diariamente en La Voz de Galicia, llevará adelante una obra sin parangón, tan personal como gallega y universal, que ha hecho de él el humorista gráfico más relevante desde Castelao. Nadie ha innovado tanto formalmente ni ha descrito como él los profundos cambios experimentados por Galicia en los últimos 50 años. Este artículo profundiza en las claves de su particular universo artístico.
\end{abstract}

Palabras clave: Xaquín Marín; Galicia; humor gráfico; prensa.

\section{Xaquín Marín: art and commitment in Galician cartoon}

\begin{abstract}
Towards 1970 a new period of splendour starts in the Galician cartoon with Xaquín Marín as one of its major protagonists. The cartoonist from Ferrol, who draws daily for La Voz de Galicia since 1988, will carry out a work without parallel, as personal as Galician and universal, that has become him the most important cartoonist from Castelao. No one has innovated so much nor has described as him the deep changes experienced by Galicia in the last 50 years. This article delves into the keys of his particular artistic universe.
\end{abstract}

Keywords: Xaquín Marín; Galicia; cartoon; press

Referencia normalizada

Caballero Wangüemert, F. (2016) Xaquín Marín: arte y compromiso en el humor gráfico gallego. Historia y Comunicación Social. Vol 21, número 2, páginas 321-341.

Sumario: 1. Introducción. 2. Estado de la cuestión. 3. Metodología. 4. Xaquín Marín y el resurgimiento del humor gráfico gallego. 5. Trayectoria profesional de Xaquín Marín. 6. El universo de Xaquín Marín. 6.1. La forma. 6.1.1. La viñeta como obra de arte. 6.1.2. Una estética tan personal como gallega. 6.2. El contenido. 6.2.1. La actitud. Un humorista sarcástico. 6.2.2. La temática. La obsesiva presencia de Galicia. 7. Conclusiones. 8. Referencias bibliográficas. 


\section{Introducción}

El humor gráfico en la prensa debe ser entendido hoy como un ejercicio de periodismo de opinión, similar a la columna, aunque la de la viñeta sea, ciertamente, una opinión sui géneris por su desenfado y desestructuración, lo que ha llevado a Paniagua (2011: 162) a calificarla de opinión no solo dibujada, sino también "desdibujada".

Desde la Transición, los humoristas gráficos gallegos vienen desempeñando eficazmente en la prensa del país esta función de cronistas o notarios de la actualidad. Entre todos ellos destaca muy especialmente Xaquín Marín (Ferrol, A Coruña, 1943), cuya vocación artística y cuyo compromiso ético han hecho de él un excelente ejemplo de que el humor gráfico puede ser una feliz mezcla de arte y periodismo.

Este artículo tiene dos objetivos fundamentales: describir las principales fases de la trayectoria humorística de Xaquín Marín en la prensa y descubrir las claves de su particular universo ético y estético.

Se ha partido de la hipótesis de que el dibujante ferrolano ha construido durante los últimos 45 años una obra humorística sin parangón en la prensa gallega, tanto por su innovación plástica como por su particular cosmovisión de Galicia.

\section{Estado de la cuestión}

Los estudios dedicados al humor gráfico en España son, por lo general, recientes y de gran disparidad. Entre los pioneros destacan, en el primer tercio del siglo XX, los ensayos sobre la caricatura y el humorismo del crítico José Francés, promotor de los primeros Salones de Humoristas. Clásicos son ya los de Iván Tubau sobre el chiste gráfico en la prensa española de posguerra (1973) -reeditado con profusión en 1987- y de Luis Conde Martín sobre la historia del humor gráfico en España (2002 y 2005). En los últimos años se observa un cierto impulso de la investigación en este campo, con estudios que relacionan el humor gráfico con las publicaciones periodísticas como soporte, como las tesis doctorales de Natalia Meléndez (2005) o Francisco Segado Boj (2008) sobre el humor gráfico en la prensa española durante la Transición, la primera centrada en el diario El País. En las obras enfocadas en la etapa predemocrática, y dentro del análisis del llamado boom del humor gráfico, se observa una sobreabundancia de publicaciones sobre las revistas satíricas de los 70. En cuanto a las monografías sobre humoristas gráficos, en los últimos tiempos han aparecido sendos libros sobre Tono (2012), Chumy Chúmez (2011) o Máximo (2015).

En Galicia, el humor gráfico sigue siendo tema poco investigado. Lo más parecido a una historia general del género lo encontramos en el libro de Lalo Vázquez Gil El humor gallego en los medios de comunicación, donde se habla también literatura, teatro, cine y radio. El autor más investigado ha sido, sin duda, Alfonso Daniel Rodríguez Castelao, con estudios clásicos como la biografía de Valentín Paz Andrade (1982) o los de José Antonio Durán, y otros más recientes de Siro López. Respecto 
a la etapa anterior a Xaquín Marín, hay que destacar también los trabajos de Siro López y Julio Neveleff sobre José María Cao (el primer gran caricaturista gallego); la colección "Os Nosos Humoristas", de Clodio González Pérez, sobre Castelao y otros cinco caricaturistas de su tiempo (Ignacio Vidales Tomé, Roberto Eduardo Padín, Carlos Maside, Xaime Prada, Manuel Torres y Álvaro Cebreiro); y el libro del propio González Pérez sobre Antonio Tomé Taboada, Atomé (Atomé. O debuxante e humorista de Santa Comba, 2000). Entre la escasa investigación existente respecto a los últimos cuarenta años destaca el libro de Alberto Pascual Carballo sobre las revistas de humor fundadas en las décadas de 1980 y 1990 (Humor gráfico galego. Da transición ao século XXI, 2009) o el trabajo de doctorado que Silvia Roca hizo en la Universidad de Santiago sobre la labor editorializante de las caricaturas de Siro López (Ferrol, 1943) en La Voz de Galicia (Humorismo e comunicación. Siro López e os editoriais de La Voz de Galicia, 2008, inédito). Agustín Fernández Paz ya había hecho ya una pequeña aproximación a la figura de Xaquín Marín, centrada fundamentalmente en sus tiras y planchas, en el prólogo de Dos pés á testa (1986).

\section{Metodología}

Para realizar esta investigación se han utilizado fundamentalmente dos métodos: la observación de viñetas y la entrevista en profundidad. En cuanto al primero, se han consultado todas las antologías de viñetas publicadas por el humorista, lo que ha supuesto la observación de cerca de 500 ilustraciones más otras mil contenidas en el CD-Rom que acompaña a una de ellas.

Respecto al segundo método, se ha entrevistado en profundidad al dibujante, con quien se tuvo un encuentro personal en Fene el 4 de octubre de 2012.

\section{Xaquín Marín y el resurgimiento del humor gráfico gallego}

El humor gráfico gallego vivió su edad de oro antes de la Guerra Civil, sobre todo en las décadas de 1920 y 1930. Fue entonces cuando Alfonso Daniel Rodríguez Castelao (Rianxo, 1886-Buenos Aires, 1950) creó propiamente el género galleguizando la caricatura síntesis de clara impronta modernista que se puso de moda en todo el mundo. Castelao desarrolló una espléndida obra, entre la que destaca su álbum Nós (1931) y la serie "Cousas da vida", que publicó desde 1923 en los diarios vigueses Galicia, Faro de Vigo y El Pueblo Gallego. El ilustre dibujante y político fundó una amplia y fecunda escuela de humoristas gráficos, entre los que destacan Carlos Maside, Álvaro Cebreiro o Manuel Torres.

La Guerra Civil puso fin abruptamente a esta edad de oro. Algunos humoristas fueron asesinados, otros tuvieron que exiliarse y el resto permaneció callado. Comenzaron entonces tres décadas de censura y decadencia artística, que terminaron hacia 1970 con la irrupción de los tres caricaturistas gallegos que constituirían los pila- 
res del brillante resurgimiento que el género experimentó desde entonces: Fernando Quesada (Vigo, 1933), Siro López y Xaquín Marín. El primero se había iniciado en Faro de Vigo en 1961 y colaboraba con éxito en la prensa de Madrid desde 1964 (Arriba, Pueblo), pero fue a partir de 1970 cuando empezó a hacer las viñetas en gallego y con temática gallega que le harían famoso. Siro (siempre ha firmado así, solo con su nombre) y Xaquín Marín se estrenaron en el humor gráfico en 1970 y 1971, respectivamente, en Chan, la revista gallega editada en Madrid que dirigía el periodista compostelano Raimundo García Domínguez, Borobó.

La labor de Quesada en Faro y de Siro y Xaquín Marín en El Ideal Gallego de A Coruña durante los años 70 apuntaba ya este resurgimiento que estallaría en las dos décadas siguientes. El punto de inflexión fue el Manifiesto en defensa del humor que Siro y Xaquín Marín lanzaron en 1983, acompañando a la exposición conjunta de dibujos de humor que presentaron de forma itinerante por toda Galicia durante casi dos años. De esta iniciativa nació en 1984 el Museo del Humor de Fene, el primero de sus características de la península ibérica, que desarrolló una extraordinaria labor de dinamización del humor gráfico en Galicia. El resurgimiento del género se confirmó con el trabajo en la prensa diaria gallega de un grupo de excelentes humoristas, como Chichi (Xesús) Campos, Xosé Lois (González Vázquez), Gogue (José Rodríguez López) y Pepe Carreiro, y con el desarrollo de otras iniciativas, como los Encuentros de Humoristas de O Condado (1984-1988), las revistas de humor Can sen Dono (1983-1991), Xo! (1993-2000) y Sapoconcho (boletín del Museo del Humor, 19942000) y la Bienal de la Caricatura de Ourense (1992-2008).

\section{La trayectoria artística de Xaquín Marín}

Xaquín Marín nació en Ferrol en 1943, pero ha vivido siempre en Fene. Desde 1971 ha desarrollado una sobresaliente carrera profesional como humorista gráfico, ilustrador, cartelista y autor de cómic. Su primera vocación fue la pintura, que cambió por la incipiente historieta tras su encuentro en la capital de España con el pintor coruñés Reimundo Patiño, quien por aquel entonces andaba experimentando con este nuevo arte. Marín es uno de los pioneros del cómic: de hecho, fue al autor de la primera historieta publicada en la prensa gallega después de la Guerra Civil ("O emigrante", 1971, en la revista Chan) y coautor del primer álbum gallego de cómic (2 viaxes, 1975, con Patiño). Pero publicar historieta en la España de la época tampoco era fácil, por lo que desembocó en el humor gráfico, para el que desde siempre mostró una gran predisposición.

Como humorista gráfico ha colaborado en más de una treintena de publicaciones, la mayoría gallegas (El Ideal Gallego, La Voz de Galicia, A Nosa Terra, Teima...) pero también de Madrid (Hermano Lobo, La Codorniz, Gaceta Universitaria, Pueblo...) e incluso del extranjero (Norte de México, Bronkit de Portugal, Ouest-France y Le Telegramme de Francia).

En su trayectoria como humorista gráfico destacan siete etapas principales: 
1. Chan (1971). Fue en esta revista quincenal gallega editada en Madrid y dirigida por Borobó donde se inició en el humor gráfico con cuatro planchas.

2. Hermano Lobo (1972). En el famoso semanario que desbancó a La Codorniz no llegó a publicar ninguna viñeta o tira, pues Chumy Chúmez (José María González Castrillo), fundador de la publicación, las consideró demasiado underground para la revista. A cambio, el director, Ángel García Pintado, le retó a escribir artículos de humor, algo que Marín nunca había hecho ni volvería a hacer. Así, en Hermano Lobo el humorista gallego publicó sus únicos cuatro trabajos como escritor humorístico.

3. La Codorniz (1972-1977). La colaboración de Marín con la revista española de humor más importante del siglo XX coincidió con los últimos cinco años de la dirección de Álvaro de Laiglesia. Marín comenzó haciendo viñetas llenas de un marcado humor negro, influidas por el francés Roland Topor. El humorista gallego llegó a tener una presencia importante en La Codorniz, firmando cuatro portadas y tres contraportadas. En La Codorniz vieron la luz por primera vez sus famosos pies pisoteando gente, que no se había atrevido a publicar ni Triunfo, la revista española más progresista de la época.

4. El Ideal Gallego (1974-1988). En diciembre de 1974 Marín comenzó a publicar en el diario coruñés El Ideal Gallego, en el suplemento de los domingos, su personaje de Gaspariño, un niño del ámbito rural que reflexionaba como un filósofo. Aunque el personaje era un menor, se trataba de humor para adultos, en la línea de Mafalda, del argentino Joaquín Lavado, Quino. A comienzos de 1975 pasó también a publicar la viñeta editorial, labor en la que se turnaba con otro grande del humor gráfico gallego de los últimos 50 años: Siro.

5. Teima (1976-1977). Fue la primera revista publicada en Galicia íntegramente en gallego después de la Guerra Civil. Marín publicó allí su tira de Caitano, un paisano que filosofaba con la sabiduría de los labregos gallegos.

6. A Nosa Terra (1977-1982). En el renacido semanario nacionalista que en los años 20 y 30 del siglo XX había sido el órgano de expresión de las Irmandades da Fala y del Partido Galeguista, Marín convirtió en tira sus viñetas de los pies, dando lugar a la serie "Historias de esmagados" (de esmagar, aplastar). También creó la tira de D. Augusto, un cacique que tenía como antecedente al D. Carcundio que había dibujado en La Codorniz.

7. La Voz de Galicia (desde 1988). Marín lleva ya casi 30 años colaborando en La Voz de Galicia, el periódico de A Coruña que es hoy el cuarto diario español en difusión. Después de haber publicado durante muchos años una viñeta diaria en Opinión, desde 2006 desarrolla diariamente la serie de Isolino, su alter ego en la tercera edad. En Xatentendo.com, el suplemento semanal de humor que el diario publicó en 2000-2001, desarrolló la serie de Coio, un cromañón, y en Golfiño, la revista infantil que La Voz editó durante un tiempo, creó los personajes de Tonecho y Palleiro. 
Paralelamente a su trabajo artístico, hay que destacar su gestión al frente del Museo del Humor de Fene, que dirigió desde su creación en 1984 hasta 2008. Esta doble faceta le ha dado una proyección internacional que ha hecho que haya sido reclamado como jurado en algunos de los concursos de humor gráfico más importantes del mundo, como el Salão Internacional de Humor de Piracicaba (Brasil) y el World Press Cartoon de Lisboa y el PortoCartoon World Festival de Oporto (Portugal).

Además, ha sido galardonado con premios tan prestigiosos como el Paleta Agromán (1982 y 1991), el Premio Galicia de Comunicación (1984, 1989, 1996 y 1997), el Primer Premio de la Bienal de Humor de Gabrovo (1987), el Trofeo Amadora Cartoon del XXV Festival Internacional de Cómic de Amadora (Portugal, 2014) y el Premio de la Crítica de Galicia de Artes Plásticas (2015).

\section{El universo de Xaquín Marín}

Sin temor a equivocarnos, podemos considerar a Marín como el humorista gráfico gallego más relevante desde Castelao, porque ningún otro ha innovado tanto gráficamente, con un estilo tan personal como gallego, ni ha contado como él los profundos cambios experimentados por Galicia en los últimos 50 años, construyendo con la temática de este pequeño país una crónica de valores universales. Marín ha creado, en definitiva, una obra tan personal como gallega y universal, excelente ejemplo de que el humor gráfico puede y deber ser una feliz mezcla de arte y periodismo.

\subsection{La forma}

\subsubsection{La viñeta como obra de arte}

Frente a aquellos que defienden el dibujo de humor de usar y tirar, hecho a prisa para no distraer la atención del lector sobre el mensaje, Marín no tiene ningún reparo en confesar que intenta hacer de cada viñeta una obra de arte: "Algunos consideran que el cartoon, el dibujo diario, es casi de usar y tirar, pero yo me resisto y creo que es un modo de hacer arte como otro cualquiera" (Conde, 2005: 526). Y a fe que lo consigue, porque tiene obra en doce museos de siete países.

Son muchos los autores que creen que el humor gráfico por excelencia, el más puro y requintado, es el que no tiene palabras (Tubau, 1987; López, 1997), y es precisamente en las viñetas mudas donde la excelencia de Marín se pone especialmente de manifiesto por la fuerza y la vitalidad de su dibujo.

La apuesta del humorista ferrolano por la viñeta como obra de arte tiene cuatro claves:

1. La prolijidad de los primeros planos. Sus características viñetas en blanco y negro (luego ha trabajado también en color, con resultados igualmente brillan- 
tes) presentan un esmerado tratamiento gráfico, caracterizado por laboriosos rayados con los que crea luces, sombras y, en definitiva, volúmenes.

2. El cuidado de los fondos. Frente al espacio en blanco de los fondos indefinidos y multifuncionales predominantes hoy en día en el humor gráfico, Marín cuida hasta el detalle los segundos planos, en los que se revela como un maestro de la caricatura síntesis, en la línea de Castelao.

3. El uso de perspectivas audaces y composiciones calculadas, deudoras, sin duda, de sus cómics. Marín utiliza todo tipo de encuadres, desde el plano detalle al panorámico. El punto de vista suele elevarse ligeramente, otorgando a la viñeta una gran profundidad de campo, con una perspectiva muchas veces oblicua. Respecto a la composición, Marín tiende a equilibrar los pesos plásticos, dando más presencia a los lados que al centro, de modo que aquellos envuelven este con la ayuda del bocadillo de texto, que ocupa todo el tercio superior de la viñeta. Esto produce una composición en forma de u o uve, porque los suelos redondeados ayudan a que los pesos gráficos de los lados se inclinen hacia afuera.

4. La singularidad de los bocadillos. Los globos o bocadillos de texto constituyen un elemento plástico más de la viñeta. Las letras son blancas sobre fondo negro y se enlazan unas con otras gracias a la prolongación de sus rasgos.

\subsubsection{Una estética tan personal como gallega}

En un momento en que los humoristas gráficos gallegos -y no solo gallegos- estaban influenciados por La Codorniz, y particularmente por Antonio Mingote, Marín, que se había iniciado en la famosa revista, escapa a ese influjo e intenta conectarse a la tradición gallega. El dibujante ferrolano transforma la caricatura modernista alemana, galleguizada por el autor de "Cousas da vida", dotándola de una fuerza y una solidez que hacen recordar lo mejor del románico y del barroco gallegos. Crea un estilo profundamente original, al tiempo que hondamente gallego, vinculado a la tradición del arte popular teorizada por Rafael Dieste, Luis Seoane o Reimundo Patiño. Estos autores vinculan esta línea estética con la tradición atlántica y nórdica, en oposición a la cultura clásica, mediterránea, y encuentran en ella una serie de constantes estilísticas que, en su opinión, denotan la psicología propia del pueblo gallego y se repiten desde los petroglifos prehistóricos hasta la obra de los "novos" o "renovadores" en el siglo XX (Carlos Maside, Arturo Souto, Manuel Colmeiro, Luís Seoane, Manuel Torres, Laxeiro [José Otero Abeledo]).

En sus viñetas se pueden detectar las características que Seoane y Patiño creen recurrentes en la tradición plástica gallega:

1. El hieratismo, la apariencia pétrea o la estética del granito, que nace de un tratamiento esquemático de las figuras que las convierte en auténticos arquetipos del pueblo, y les da una serenidad atemporal y una rotundidad escultórica que las vincula a la tradición románica y barroca. 
2. El horror vacui o la acumulación de las formas, que aglutina planos y volúmenes, tendiendo a formar masas compactas siguiendo la ley de máximos contactos.

3. Las formas redondeadas, que tienen que ver con el movimiento encadenado y el concepto dinámico de la línea, en el que ninguno de los trazos principales queda sin ser recogido por otros.

4. Los volúmenes simétricos, que se refieren al tipo de composición en uve descrito más arriba.

\subsection{El contenido}

\subsubsection{La actitud. Un humorista sarcástico}

Marín es, fundamentalmente, un humorista sarcástico. Es decir, de los tres géneros que Siro López (1999: 38) distingue en el humor -la comicidad, la sátira y el humorismo-, cultiva, sobre todo, este último. El humorismo persigue la sonrisa y apela a los sentimientos. Para Fernández de la Vega (1983: 149), es un esfuerzo por comprender, por responder con sentido a una situación conflictiva que se mueve en un horizonte de comicidad y tragedia, de risa y llanto. Una actitud que va acompañada de una expresiva sonrisa de comprensión.

Según Fernández de la Vega (1983: 93, 125), hay dos tipos de humorismo: el benévolo y el sarcástico o negro. El primero no quiere reír a tontas y a locas, sino comprender, disculpar y sonreír. Intenta poner obstáculos a la comedia y para eso lo que hace es implicarse sentimentalmente en el conflicto, ennobleciendo a los personajes. Por el contrario, el segundo es el que hace de tripas corazón por no desesperarse, por caricaturizar la tristeza. Intenta poner obstáculos a la tragedia y para eso retira el corazón, objetiva el conflicto y le quita, más o menos irónicamente, nobleza a la víctima.

Marín practica, fundamentalmente, un humorismo sarcástico, "que se ríe de nuestros defectos, incluidos los suyos", en opinión de Siro López (comunicación electrónica, 25-2-2015), y que a veces llega a ser negro. De hecho, las primeras viñetas de Marín en La Codorniz - muy influidas por el francés Roland Topor- entran de lleno en esta categoría.

Marín es un moralista - denuncia vicios sociales con el fin de que se corrijan-o, mejor, un humanista. Detrás de toda su obra hay una denuncia de la deshumanización que caracteriza a la sociedad actual. Por eso Antón Cortizas (2001: 6) lo ha tildado de "humanista gráfico" o "humanorista caligráfico", y Felipe Senén ha calificado su humor de "humor de la deshumanización" (comunicación electrónica, 24-5-2013). 


\subsubsection{La temática. La obsesiva presencia de Galicia}

La obra de Marín está marcada por la obsesiva presencia de la realidad gallega, como ha escrito Fernández Paz (1986: 10). Marín es uno de los más fieles cronistas de la Galicia de su tiempo, la de entre siglos. Ningún otro humorista ha contado como él los profundos cambios experimentados por Galicia a lo largo de los últimos 45 años. En este sentido, ha dejado claras muestras de que el humor gráfico puede y debe ser un requintado ejercicio de periodismo.

Esta crónica de la Galicia de entre siglos presenta dos características que la abren al mundo: su intemporalidad y su universalidad. En efecto, Marín manifiesta una preferencia casi absoluta por la intemporalidad o la actualidad permanente frente a la inmediata y perecedera, esa que hace del humor gráfico algo de "usar y tirar", en palabras del propio humorista (Lorenzo, 2014, febrero 11).

O humor actual abusa do tema político e céntrase moito na actualidade. Eu, sen poderme evadir totalmente diso, procuro que os meus personaxes sexan máis intemporais e que o que lles pase poida tamén ocorrer noutro tempo pasado ou futuro. $\mathrm{O}$ humor do día é moi perecedoiro: hoxe ensínaslle a un rapaz un chiste no que aparece Fraga e xa non sabe de quen se trata. Porén, os que fixo Castelao hai sesenta anos continúan estando vixentes (Caballero, 2012: 56).

Respecto a la universalidad, sin duda de Marín se puede decir lo que afirma Siro de Castelao: "Poucos humoristas gráficos do mundo acadaron o seu poder de comunicación e, desde logo, será difícil atopar algún que fixese unha obra de valores universais coa temática dun pequeno país da fisterra europea" (López, 1996: 74). La Galicia de Marín no se cierra en sí misma. Su discurso es tan gallego como universal. El humorista ferrolano sobrepasa el costumbrismo y se abre a horizontes nuevos, universales y, al mismo tiempo, más enraizados en la cultura gallega. Como dice Fernández Paz (1997: 26-27), Marín

fala do que sente e do que mellor coñece: Galicia, as súas xentes, os seus problemas. Non cae no tópico dos falsos cosmopolitismos, porque sabe que só se pode ser universal desde as propias raíces. (...) sabe que ser fiel ó seu xeito de entender o mundo é o camiño para conseguir unha obra auténtica e universal.

La suya es la crónica de una Galicia en transformación y también, hasta cierto punto, en descomposición. El dibujante viene a denunciar que, en nombre de una falsa modernidad, de un cuestionable progreso, Galicia está renunciando a sus principales señales de identidad, a sus esencias como pueblo, al tiempo que no acaba de sacudirse seculares manifestaciones del abuso de poder. Así, en sus viñetas y tiras podemos identificar ocho temas principales en los que se expresa esta crisis: 1) la permanencia del caciquismo, 2) la pervivencia del machismo, 3) la sangría de la emigración, 4) los obstáculos a la normalización de la lengua gallega, 5) la contaminación cultural, 6) el desarraigo de la urbanización, 7) el descalabro ecológico y 8) los excesos de la tecnología. 
A menudo, el autor aborda estos temas a través de unos símbolos o arquetipos muy personales y de gran fuerza plástica. Los principales son: el pie y el jinete (el caciquismo), la mujer sometida (el machismo), el emigrante (la emigración), la lengua (la normalización lingüística), el descastado (la contaminación cultural), el rascacielos (la urbanización), las chimeneas (el medio ambiente) y los verterderos (la tecnología). Hay un símbolo que viene a resumir todos: el socavón con la forma del mapa de Galicia, que simboliza la depresión del país en todos los sentidos: económico, moral, anímico.

\section{1) La pervivencia del caciquismo}

De plena vigencia en los años de la producción artística de Castelao, el caciquismo ha llegado hasta nuestros días en forma de lo que se ha dado en llamar clientelismo político. Pero Marín no habla solo del caciquismo político, sino también del económico y, en general, de todo abuso de poder.

El humorista parte de un doble arquetipo que contrapone: el del paisano gallego -que representa a las clases populares gallegas: labradores, pescadores y obreros- y el del cacique. El gallego es representado con los rasgos de un labrador pobre. Marín dibuja al gallego con boina y, al principio, descalzo, para subrayar su pobreza. Por contraposición, el cacique, el poderoso, el ricachón, es un señor gordo con sombrero, gafas de sol, traje y corbata.

El abuso de poder es manifestado por Marín a través de un puñado de símbolos o arquetipos, entre los que destacan el pie y el jinete.

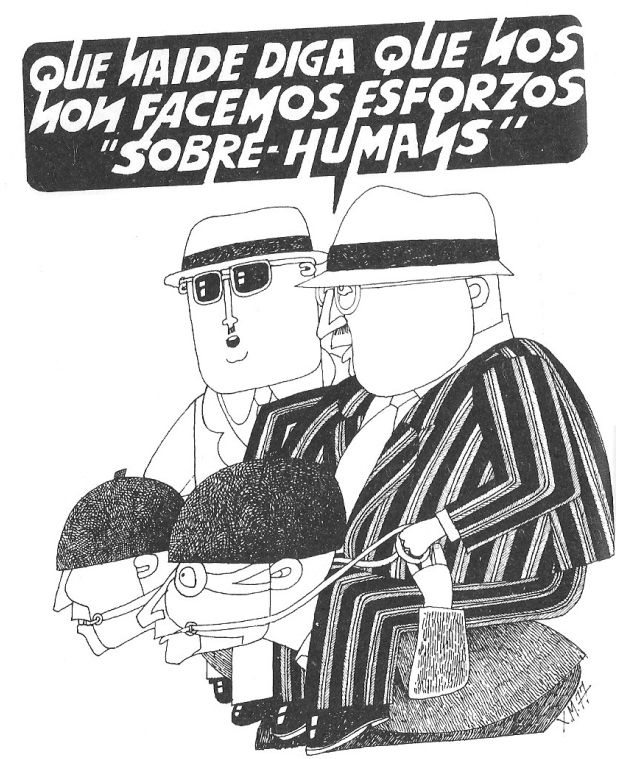

Fig.1. Marín, 1977. Fuente: Marín, 2001 (CD). 
El pie es el personaje más universal e intemporal de todos los de su autor y el que ha tenido una vida más larga. Nació en el tardofranquismo, y en esa época y en la Transición podía adivinarse en él el agonizante régimen de Franco o el franquismo sin el general que lo sustituyó hasta 1977-1978. Sin dejar de hacer una crítica al pie opresor, Marín se centra especialmente en los oprimidos (los esmagados), satirizando su falta de rebeldía, su postura acomodaticia: "Non me decato de nada, son cego"; "Os tempos cambian, agora usa desodorante"; "É un consolo saber que moitos nin isto teñen".

Los jinetes son señoritos montados a caballo en paisanos que llevan las riendas en la boca. El paisano responde al arquetipo del labrador gallego, mientras que el señorito tiene los atributos físicos del cacique. Los jinetes hacen a sus cabalgaduras comentarios cínicos: "Pra que vexan que non son egoísta voulle dar unha boa carreira a iste" (1976); "Que nadie diga que non facemos esforzos "sobre-humáns" (1977) (figura 1); "Hai que ser ecoloxista, nada de motores" (1995).

2) La pervivencia del machismo

Si Marín representa al varón gallego con una boina, sobre todo hasta entrada la década de 1980, a la mujer gallega la dibuja con un pañuelo en la cabeza y zocas. De ahí surge el arquetipo de la mujer sometida, dominada: esa misma gallega doblada bajo el peso de una enorme gavilla sobre su espalda. Es un arquetipo del sometimiento, pero simboliza también las cualidades que la Generación Nós daba a la mujer gallega: trabajadora, fuerte, sacrificada.

Estas mujeres así caracterizadas hacen reflexiones humorísticas sobre su triste condición: "Ogallá os homes galegos tamén creeran que as mulleres debemos estar na casa (1978)"; "Hai que ter ben forza para ser do sexo débil" (1980); (ante un cartel del Día Internacional de la Mujer Trabajadora) "Quen chegara a iso!" (1988) (figura 2).

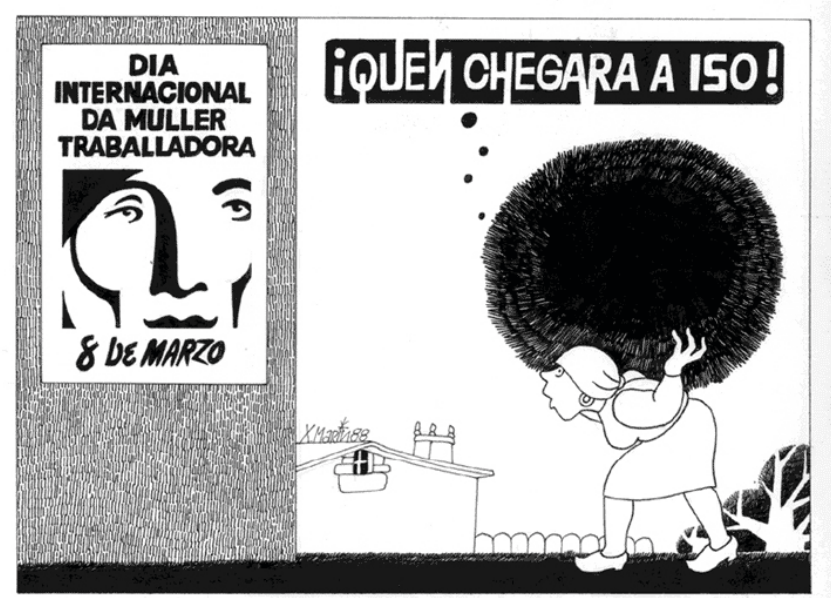

Fig.2. Marín, 1988. Fuente: Marín, 1997. 
El hombre machista suele ser presentado como tirano y vago, como ya pasaba en las "Cousas da vida" de Castelao en los años 20: "Nesta casa non hai machismo, dígoo eu e punto" (1990). El mejor aliado de este hombre tirano y vago suele ser el televisor. Mientras que la mujer brega con la casa y los críos, el hombre se tira en el sofá a ver la tele, de espaldas a todo. Cuando la televisión se mezcla con el fútbol, el cóctel es explosivo: "Deixade a papá, que para 10.000 partidos que ten no ano polo menos que os poida ver tranquilo" (1998).

Muchas de las viñetas de Marín sobre el machismo tienen que ver con los malos tratos. En un tema tan delicado como este, el dibujante opta por el humor negro, tal vez la única manera de abordarlos humorísticamente: "Non te queixes de malos tratos! ¡Que pensar sempre deixei que pensaras canto quixeras!" (1994); "Son moi feliz co meu home, total por unha paliza de cando en vez" (1995).

3) La sangría de la emigración

Marín comienza a hacer humor hacia 1970, un tiempo en que la secular emigración gallega no solo no había terminado aún, sino que se había reactivado con nuevos destinos (los países ricos de Europa Occidental, especialmente Alemania, Suiza y Francia). La ralentización del proceso no llegaría hasta los años 80, pero a partir de 2008 ha vuelto a alcanzar números inquietantes.

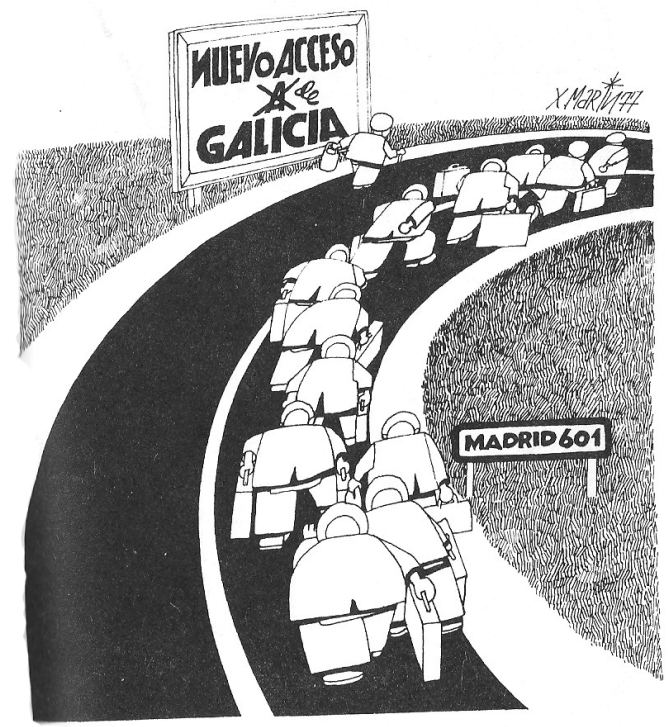

Fig.3. Marín, 1977. Fuente: Marín, 1980.

El emigrante de Marín es un paisano con boina y una maleta en la mano, representado normalmente de espaldas, yéndose. Casi siempre aparece en grupo, acentuando la impresión de salida masiva, y muchas veces el cuadro se completa con alguna 
señal de localización que nos ayuda a visualizar que lo que están dejando atrás es Galicia (figura 3).

Las ideas principales de Marín sobre la emigración son cinco:

1. La emigración en Galicia es vivida como un destino natural, inevitable: "Penso, logo emigro" (1975); "Nós, máis que porvir temos por-ir" (1977).

2. El gallego lleva Galicia siempre consigo allá donde va. En una viñeta muda de 1976 vemos un emigrante que permanece unido a su tierra a través de un cordón umbilical, y en otra de 2000, una maleta abierta que deja ver lo que su propietario no ha acabado de dejar atrás: la familia, la casa, la aldea...

3. El gallego sueña siempre con volver a su tierra: "Non teñas medo, muller, que polo menos para morrer penso voltar" (1978).

4. Hay emigrantes descastados que no quieren ser gallegos y fuera tienen más fácil vivir como si no lo fuesen: "É un parvo, foi a facer as América e as Américas o fixeron a el” (1975).

5. La emigración está descapitalizando Galicia. El gallego se marcha para intentar hacer fortuna en otro lugar y, de paso, contribuir a la construcción del país de acogida, y deja, así, sin construir el suyo: "Os galegos non teñen problemas, con emigrar arranxan todo. -Menos Galiza!" (1978).

4) Los obstáculos a la normalización de la lengua gallega

En Galicia no hubo nunca verdadero bilingüismo, sino diglosia: el castellano era -y aún es- la lengua de prestigio; el gallego, el idioma de la aldea. Marín critica la persistencia de esta realidad, destacando el complejo de inferioridad de algunos gallegos que hablan castellano para subir en la escala social.

El dibujante repasa también los tópicos más habituales sobre la lengua gallega esgrimidos por aquellos que viven de espaldas a ella: es un idioma moribundo; no sirve para la vida moderna; está politizado; están intentando imponerlo por la fuerza; para ser gallego no hace falta hablar gallego; sería mejor que los niños tuvieron más horas de inglés...

El humorista se hace eco también de las tensiones y las contradictorias situaciones generadas por el nuevo estatus de oficialidad de la lengua, como el minifundismo lingüístico y la guerra de normativas, o el paripé de algunos políticos que hablan gallego en público para ser políticamente correctos y se deshacen de él tan pronto entran en su esfera personal.

Para hablar de este tema, Marín utiliza dos símbolos: la lengua y las Letras Gallegas. El humorista dibuja una gran lengua física como símbolo de la otra, del código verbal. A veces la presenta saliendo de una boca -domesticada, amordazada, callada a la fuerza, pero también como un cañón, recordándonos que puede ser un arma poderosa-, mientras que otras cobra vida propia y aparece exenta, animada, como un personaje más, enferma en la cama (figura 4) o muerta en procesión fúnebre. 


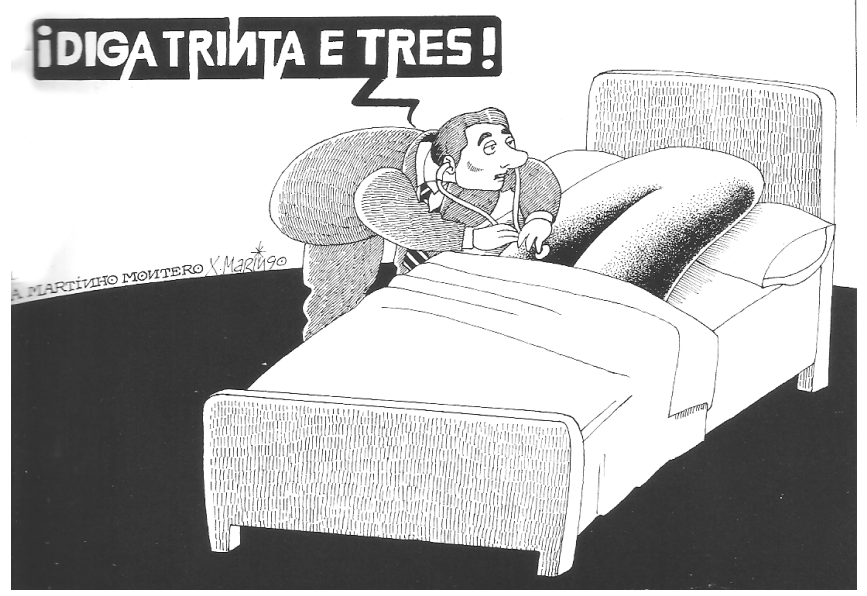

Fig. 4. Marín, 1990. Fuente: Marín, 1997.

El Día de las Letras Gallegas es una celebración instituida en 1963 por la Real Academia Galega para homenajear a aquellas personas que han destacado por su creación literaria en gallego y su defensa de esta lengua. Marín denuncia la hipocresía de las personas e instituciones que solo otorgan atención al gallego ese día, ignorándolo - cuando no hostigándolo- el resto del año.

Marín representa el Día de las Letras Gallegas animando algunas letras del abecedario, a las que pone boina o monteira, como si fueran paisanos. El humorista refleja la debilidad del gallego representándolas heridas o mutiladas. Desfilan festivamente mientras en primera fila aplauden hipócritamente algunos señoritos que nunca utilizarían el gallego.

\section{5) La contaminación cultural}

Galicia presumió siempre de su tradición, de ser uno de los pueblos de España que mejor supieron protegerla a lo largo del tiempo. Sin embargo, en los últimos 60 años, ha sufrido un proceso de transformación en todos los campos que ha puesto en riesgo lo mejor de su tradición. En nombre de un falso progreso, de una falsa modernidad, Galicia está renunciando su identidad cultural, a sus raíces, a lo mejor de sus tradiciones, se lamenta el humorista. Marín no está en contra del progreso, pero quiere que dialogue con la tradición, en vez de negarla. A la modernidad hay que abrirse desde la tradición; al mestizaje hay que abrirse desde la identidad propia, sostiene el humorista: "Os que tanto falades de mestizaxe cultural, teredes en conta que para facela é preciso ter viva a cultura propia" (1998).

El dibujante juega aquí con el arquetipo del descastado: el hombre o la mujer contaminados culturalmente, cuando no colonizados. Va vestido como un guiri, un extravagante turista extranjero, con una gorra con vísera típicamente yanqui, gafas de sol, camisa estampada, shorts, calcetines a rayas... Si el arquetipo es un joven, el patetismo se acentúa: gorra con visera yanqui, camiseta de la NBA (la liga de 
baloncesto de los EEUU), pantalones piratas, zapatillas deportivas, cascos de música, monopatín en la mano... Estos jóvenes dan pie a textos como: "E pensar que moita xente só atopa contaminación no fume, nos verquidos e no lixo" (1992) (figura 5); "Entón ti aseguras que non estás colonizado? -Yes!" (1999); "Non me preocupa perdé-la identidade, o que me preocupa é que se decaten que somos de aldea" (1998).

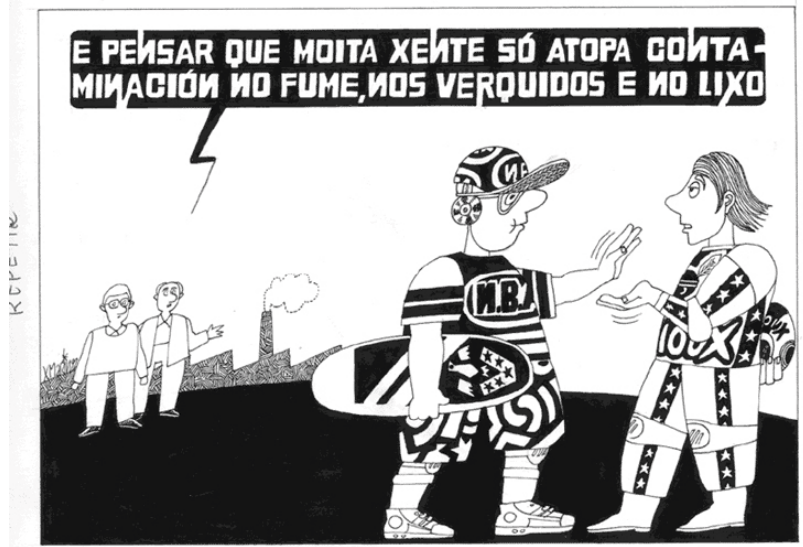

Fig. 5. Marín, 1992. Fuente: Marín, 2001 (CD).

En este proceso de transformación cultural de la Galicia de los últimos 60 años, la televisión ha jugado un papel fundamental, colocándose a la vanguardia del proceso. Para Marín, la televisión se transforma en un elemento estupidificante, que aísla a las personas de la realidad y de sus semejantes. Son muchas las viñetas en las que Marín dibuja a toda una familia absorta delante del televisor. En una, el padre dice: "Teño que comunicarvos algo trascendental, a televisión leva media hora averiada" (2000). Los demás lo miran incrédulos. En otra, el hijo más joven protesta: "¡Mamá, que levamos tres días sen comer!", y el resto, fastidiado, le hace callar con un prolongado “;chiiiiissst!" (1988).

6) El desarraigo de la urbanización

Galicia fue secularmente un país de labradores y marineros, con una población mayoritariamente rural y desperdigada geográficamente. Sin embargo, a partir de 1960 encontramos un rapidísimo e imparable proceso de urbanización, cuyo índice pasó del 23,8\% en 1960 al 70,47\% en 2005.

Marín habla aquí de la tensión entre el campo y la ciudad, entre el mundo rural y el urbano. Denuncia que el rural está muriendo por el avance de una urbanización descontrolada, y echa de menos un equilibrio, una armonía entre los dos medios. El dibujante no idealiza el campo. Critica, por ejemplo, el minifundismo, uno de sus defectos: "Toda a vida xuntando para un tractor e agora non me colle no minifundio" (1999). Pero lo presenta - el campo- como un espacio humanizado, lleno de elemen- 
tos, naturales o artificiales -árboles, colinas, leiras, corredoiras, casiñas, hórreos, carros, igrexiñas-que dan sensación de placidez, de comunión con la naturaleza.

Frente a la placidez del mundo rural, Marín presenta la ciudad como un espacio de estrés y deshumanización: rascacielos, automóviles, humos, ruidos. Los rascacielos son uno de los símbolos más plásticos del autor. Normalmente los llena de pequeñas ventanas, dándoles la apariencia de colmenas, pero a veces son bloques cerrados, macizos, que aumentan la sensación de soledad, de incomunicación, de claustrofobia.

En cuanto a los automóviles, Marín los enfrenta con los carros, igual que a las carreteras y a las autopistas con las corredoiras, y denuncia la locura del tráfico en las ciudades, con su importante contribución a la polución ambiental y acústica. Otra invasión de la tierra, en este caso con el asfalto.

El mensaje central de Marín es que la ciudad está invadiendo el campo, que el cemento está devorando la tierra: "Pronto non poderemos ter amor á nosa terra, só ó noso cemento" (1991); "Aquí hai moito desertor do arado! -Pois isto hai pouco era campo, así que o que hai é moito invasor do rañaceos" (1999). Como siempre, son las viñetas mudas las que mejor expresan esta confrontación. En una de 1999, Marín dibuja una represa intentando contener el avance de un montón de rascacielos sobre un labrador que sacha una finca (figura 6).

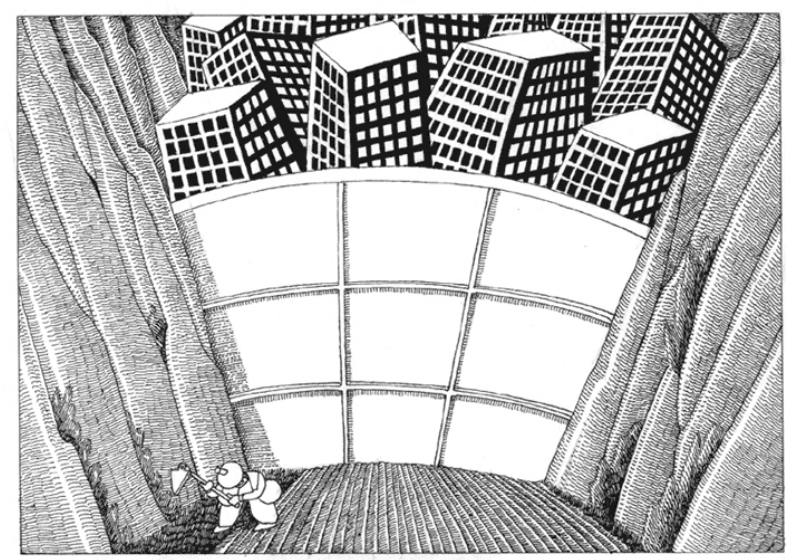

Fig.6. Marín, 1990. Fuente: Marín, 2001 (CD).

7) El descalabro ecológico

Galicia, una sociedad tradicionalmente agraria y marinera, ha experimentado desde los años 60 del siglo pasado un proceso de industrialización que a veces tiene como consecuencia la desaparición del paisaje natural y la degradación del medio ambiente. Esto es lo que denuncia Marín. En una viñeta de 1976, un hombre mira las chimeneas humeantes de una fábrica y dice: "É estraño, ás vegadas o progreso 
é recuar". En otra de 1977, una multitud huye de una nube de humo mientras grita: “¡Socorro! ¡A industrialización!” (figura 7).

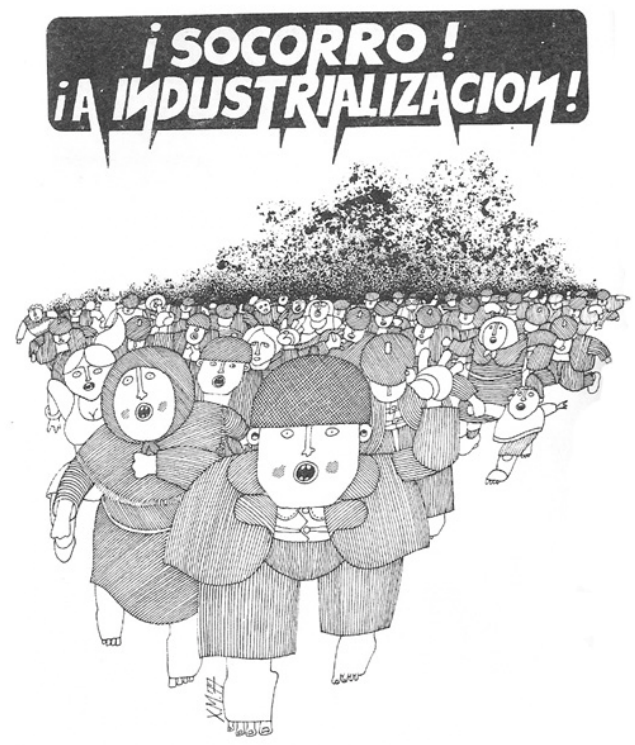

Fig.7. Marín, 1980. Fuente: Marín, 1980.

Los empresarios cínicos y sin escrúpulos son, en este sentido, víctimas predilectas del humorista. En su boca pone frases como: "Si, si, beneficios dá moitos, o malo é que dá noxo vir a recollelos" (1976); "Mira se son amante da natureza que para vivir busquei un sitio ben lonxe da miña fábrica" (1991).

Los incendios forestales, auténtica lacra que asola Galicia todos los años, son otra de las preocupaciones de Marín, pero, sin duda, el mayor tema medioambiental de su producción ha sido la tragedia del "Prestige", el petrolero que se hundió frente a las costas de Muxía (A Coruña) en noviembre de 2002 con 77.000 toneladas de fuelóleo, provocando la mayor catástrofe ecológica de Galicia en los últimos tiempos. En 2003, el dibujante fue promotor de la exposición Humor cru y participó en el álbum de cómic $\mathrm{H} 2 \mathrm{Oil}$, en el que docenas de ilustradores de toda España denunciaron la situación.

Marín maneja un puñado de símbolos sobre el medio ambiente: las chimeneas humeantes, los colectores que vierten productos tóxicos al mar, las máscaras de gas...

8) Los excesos de la tecnología

Marín recela de un desarrollo tecnológico que tiene consecuencias paradójicas: por un lado, libera a las personas al hacerles la vida más cómoda; por otro, las esclaviza al crearles un montón de falsas necesidades, abocándolas a un consumismo desenfrenado y vacío. 
El humorista refleja esta realidad a través del que, sin duda, es su símbolo más contundente desde el punto de vista gráfico: los vertederos, auténticas montañas de basura, de chatarra, fundamentalmente tecnológica, formadas por automóviles, motocicletas, televisores, ordenadores, neveras, lavadoras, lavabos, neumáticos, bidones, botellas (figura 8). "Hai algún autor que está sempre con iso: co lixo, con que vai comendo as cidades e terminará sendo máis grande ca elas", afirma Marín, que destaca también la "estética" de este motivo, que incluso puede llegar a ser "bonito". Para el dibujante, en el humor "búscase a estética da falla de ética, sacándolle a posible beleza a un vertedoiro de lixo ou a unha ocasión degradante" (Marín, 2000).

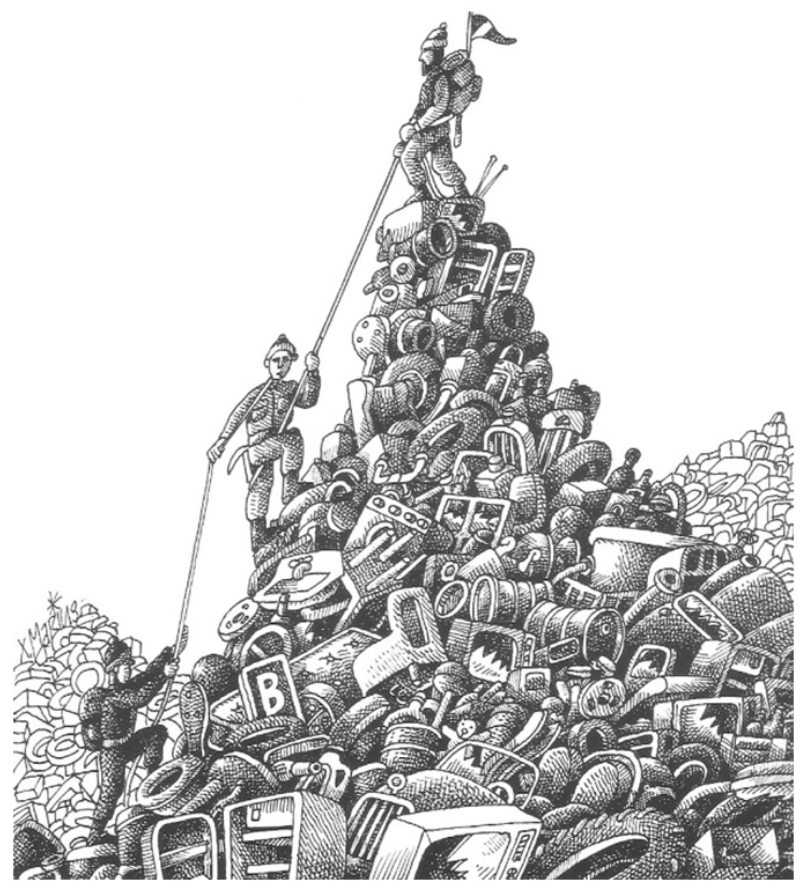

Figura 8. X. Marín, 1987. Fuente: Marín, 1997.

Otras veces, Marín dibuja unas máquinas-monstruo que nos hablan del dominio de los hombres por las máquinas y nos hacen pensar en Tiempos modernos, de Charles Chaplin, o el Gran Hermano de George Orwell. Se trata de verdaderos monstruos, maquinarias inmensas con chimeneas, tubos y apéndices de toda clase, que recuerdan los pies. De hecho, no faltan ni los esmagados. El hombre es dominado por la máquina hasta llegar a deificarla, a adorarla, como muestra una viñeta muda de 1999, titulada, justamente, Máquina adorada. 


\section{Conclusiones}

Xaquín Marín es el humorista gráfico gallego más relevante desde Castelao, tanto desde el punto de vista formal como del contenido. Nadie ha construido un universo ético y estético como el suyo.

Respecto a la forma, es el mayor innovador el humor gráfico gallego desde su ilustre antecesor. Ha transformado la caricatura modernista alemana, galleguizada por aquel, dontándola de una fuerza y una solidez que hacen recordar lo mejor del románico y del barroco gallegos. Ha creado un estilo profundamente original, al tiempo que hondamente gallego, en el que se descubren las constantes señaladas por los teóricos del arte popular de Galicia: el hieratismo de los personajes, el hórror vacui, las formas redondeadas y los volúmenes simétricos.

Marín no cree en el humor gráfico de usar y tirar. Aspira a hacer obras de arte. Las claves de este logro, además de la actualización de las formas tradicionales gallegas, son la prolijidad de los primeros planos, el cuidado de los fondos, la esmerada composición de la viñeta y la singularidad de los bocadillos.

En cuanto al contenido, ha sido capaz de construir una obra intemporal y universal con la temática de un pequeño país. Habla de los defectos de una sociedad -la gallega- que son también las de muchas otras, especialmente en este mundo globalizado.

El humorista ferrolano es uno de los más fieles cronistas de la Galicia de su tiempo. Nadie ha contado como él los profundos cambios experimentados por la actual comunidad autónoma durante los últimos 45 años. En su obra se identifican ocho temas recurrentes que tienen que ver fundamentalmente con el abuso de poder o la pérdida de la identidad colectiva: 1) la permanencia del caciquismo; 2) la pervivencia del machismo; 3) la sangría de la emigración; 4) los obstáculos de la normalización lingüística; 5) la contaminación cultural; 6) el desarraigo de la urbanización; 7) la degradación del medio ambiente; y 8) los excesos de la tecnología.

A menudo aborda estos temas a través de unos símbolos o arquetipos muy personales y de gran fuerza plástica. Los principales son: el pie y el jinete (el caciquismo), la mujer dominada (el machismo), el emigrante (la emigración), la lengua (los obstáculos de la normalización lingüística), el descastado (la contaminación cultural), el rascacielos (el desarraigo de la urbanización), los vertederos (la degradación del medio ambiente) y las máquinas-monstruo (el maquinismo). Hay un símbolo que resume todos: el socavón con la forma del mapa de Galicia, que viene a simbolizar la depresión del país en todos los sentidos: económico, moral, anímico.

Marín es, fundamentalmente, un humorista sarcástico. Intenta caricaturizar la tragedia, cayendo a veces en el humor negro, pero siempre con un poso de ternura. Como humorista, sabe que su papel es destacar lo malo para denunciarlo y ayudar a que se corrija, y en ese sentido es también un moralista, un humanista. 
A su labor como humorista gráfico en la prensa -iniciada en Madrid en 1970 (Chan, Hermano Lobo, La Codorniz, fundamentalmente) y continuada en Galicia desde 1975 (El Ideal Gallego, A Nosa Terra, La Voz de Galicia, entre otras publicaciones)- hay que sumar su papel de dinamizador del humor como fundador y director del Museo del Humor de Fene (1984), el primer museo de humor de la península ibérica, que le ha dado una gran proyección internacional.

\section{Referencias bibliográficas}

CABALlERO, F. (2012). O humor en cadriños. Cangas: Morgante.

CONDE, L. (2005). El humor gráfico en España. La distorsión intencional. Madrid: Asociación de la Prensa de Madrid.

CORTIZAS, A. (2001). Limiar. Para quen leva agochado todo o mundo na mirada. En X. Marín, Trinta e tantos con Xaquín Marín (pp. 6-7). Ferrol: edición do autor. FERNÁNDEZ PAZ, A. (1986). Limiar. En X. Marín, Dos pés á testa (pp. 5-12). Vigo: Galaxia.

(1997). A lucidez do corredor de fondo. En X. Marín, Feito a man (p. 23-25). Santiago de Compostela: Consellería de Cultura e Comunicación Social, Xunta de Galicia.

LÓPEZ, S. (1996). Castelao humorista. Santiago de Compostela: Xunta de Galicia / Centro de Investigacións Lingüísticas e Literarias Ramón Piñeiro.

(1997). Xaquín Marín, innovador do humor gráfico galego. En X. Marín, Feito a man (pp. 17-18). Santiago de Compostela: Consellería de Cultura e Comunicación Social, Xunta de Galicia.

(1999). Humor e identidade en Galicia. En M. Gondar-Portasany (coord.), Galicia fai 2000 anos. O feito diferencial galego III. Antropoloxía, vol 2 (pp. 37-49). Santiago: Museo do Pobo Galego.

LORENZO, U. (2014, febreiro 11). Xaquín Marín: “O cómic era o mellor vehículo para contar o que queriamos". Noticieirogalego.com. Recuperado el 18 de febreiro de 2014 de http://www.noticieirogalego.com/xaquin-marin/

MARÍN, X. (1980). Alcacén para gaitas. Sada: Ediciós do Castro.

(1986). Dos pés á testa. Vigo: Galaxia.

(1996). Cen pés. Sada: Ediciós do Castro.

(1997). Feito a man. Santiago de Compostela: Consellería de Cultura, Xunta de Galicia.

(2000). Díptico de la exposición de dibujos Quosquetandem. Portas Ártabras, A Coruña, del 31 de marzo al 28 de abril de 2000.

(2001). Trinta e tantos con Xaquín Marín. Ferrol: edición propia.

(2005). Xaquín Marín [50 anos en liña]. Ferrol: Concello.

MARÍN, X. Y LÓPEZ, S. (2009). O humor desde Ferrol: Siro e Xaquín Marín. Ferrol: Club de Prensa de Ferrol. 
PANIAGUA, P. (2011). El humor en los diarios. La opinión (des)dibujada. En M. L. Sánchez Calero (ed.). Géneros y discurso periodístico (pp. 157-182). Madrid: Fragua.

TUBAU, I. (1987, $2^{\mathrm{a}}$ ed.). El humor gráfico en la prensa del franquismo. Barcelona: Mitre. Edición corrixida e aumentada de TUBAU, I. (1973). De Tono a Perich. El chiste gráfico en la prensa española de la posguerra (1939-1969). Madrid: Guadarrama. 